\title{
Neutrality, Partiality, and Meaning in Life
}

\author{
Thaddeus Metz
}

\begin{abstract}
Discussion of whether values and norms are neutral or not has mainly appeared in works on the nature of prudential rationality and morality. Little systematic has yet appeared in the up and coming field of the meaning of life. What are the respects in which the value of meaningfulness is neutral or, in contrast, partial, relational, or 'biased'? In this article, I focus strictly on answering this question. First, I aim to identify the salient, and perhaps exhaustive, respects in which issues of neutrality arise in the contexts of life's meaning. In addition to providing a taxonomy of the key points of contention, a second aim is to advance reflection about them by considering the most important arguments that have been marshalled in favour of one side or the other, particularly as they appear in recent neutral positions. I conclude that meaning in life is neutral with respect to time but not any other conditions such as agents and patients, with a third aim being to point out that this makes the value of meaning different from the kinds of non/neutrality encountered in some salient conceptions of prudence and morality.
\end{abstract}

\section{Introduction}

Discussion of whether values and norms are neutral or not has mainly appeared in works on the nature of prudential rationality and morally right action. Little systematic has yet appeared in the up and coming field of the meaning of life. These days, value theorists routinely take the question of what makes a person's life meaningful (which contrasts with the more cosmic question of the point of the human race) to be distinct from considerations of prudence and morality. ${ }^{1}$ It is therefore apt to enquire into the respects in which the personal value of meaningfulness, and the sorts of reason it grounds, are

1 E.g. Susan Wolf, Meaning in Life and Why It Matters (Princeton: Princeton University Press, 2010); Thaddeus Metz, Meaning in Life: An Analytic Study (Oxford: Oxford University Press, 2013). 
neutral or are, in contrast, partial, relational, or 'biased'. In this article, I focus on answering this question.

In particular, one aim is to identify the salient, and perhaps exhaustive, respects in which issues of neutrality arise in the context of life's meaning. In rough catchwords, these concern: time (when good is preferable), agents (who fosters good), patients (whose good to foster), and means (how to foster good). ${ }^{2}$

In addition to providing a taxonomy of the key points of contention, a second aim is to advance reflection about them by considering important arguments that have been marshalled in favour of one side or the other, particularly as they appear in recent neutral positions. ${ }^{3}$ I conclude that, at present, there are weighty reasons to believe that a meaningful life is one shot-through with non-neutrality. Although subjectivism is naturally associated with that view, one has strong reason to believe it even if one denies that meaning is merely subjective.

A third aim is to point out respects in which the forms of non/neutrality that I argue are inherent to meaning often differ from those in salient conceptions of prudence and morality. In particular, I argue that reasons of meaning are time-neutral in a way that hedonism about prudential reasons is not, and that it is non-neutral in several ways that consequentialism about moral reasons is not.

I begin by analyzing concepts, making it clear what debate regarding the nature of life's meaning is about and how I employ the neutral/non-neutral and subjective/objective distinctions. Then, I use the bulk of this article to address four major disputes about the neutrality of meaning in life or the lack thereof, concluding, roughly, that meaning in life is neutral only with respect to time, but no other conditions such as agents and patients. I conclude by noting that it would be desirable to consider elsewhere whether an explanation is available of why meaning is neutral with respect to time but not other conditions, pointing out that this structure is the inverse of utilitarianism.

\section{Meaning, Neutrality, Objectivity}

In this section I first offer an analysis of the concept of a meaningful life, and then spell out what it would mean for it to be neutral, non-neutral, objective, or subjective. After noting that the objective/neutral and subjective/non-neutral distinctions are naturally paired, I explain what it would mean for meaning to be objective/non-neutral or subjective/neutral. It is only in the following sections that I address arguments for and against neutrality.

By 'meaning in life' and cognate phrases I essentially mean an independent final good that can be exemplified by a human person to a variable degree, as opposed to a

\footnotetext{
2 Much of this article presumes, with the friend of neutrality, that at least some substantial meaning comes from promoting certain conditions that are independently good for their own sake. I do not believe that it is exhausted by such.

3 Aaron Smuts, 'The Good Cause Account of the Meaning of Life', Southern Journal of Philosophy 51:4 (2013), pp. 536-562; Ben Bramble, 'Consequentialism about Meaning in Life', Utilitas 27:4 (2015), pp. 445-459; Mark Wells, 'Meaning in Consequences', Journal of Philosophy of Life 5:3 (2015), pp. 169-179.
} 
something conferred on the human race as a whole by something external to it such as God. Here is some prima facie evidence for thinking that meaning is a distinct personal good that is reducible to neither happiness nor morality, and so merits enquiry on its own about its value-theoretic structure. ${ }^{4}$

First off, it appears coherent to think of certain activities or periods that are happy but not meaningful, at least when 'happiness' is construed in a characteristically modern way as something mental. Where happiness is a matter of feeling pleasure, liking one's condition, or getting what one wants, then it appears to be something that can be quite separate from meaning. Consider a doctor getting high on laughing gas, or eating ice cream and watching sit-coms, in front of patients suffering in ways he could prevent.

Note, too, that it is not contradictory to suppose that aspects of a life could be meaningful but unhappy, again construed mentally in some way. A nurse who works to relieve patients of pain, stench, and discharge can be supposed to acquire meaning thereby, but might well neither enjoy it, nor like it, nor want it to continue.

Similar thought experiments apply to the relationship between morality and meaning. Just because an action or inaction is morally right does not make it meaningful, or at least the degree of the latter does not track the degree of the former. For example, it would constitute a serious wrongdoing to kidnap innocent people, forcibly remove their organs, and then sell them on the black market so that one can vacation in the south of France. However, not much meaning would accrue to one's life for not engaging in such wrongdoing.

In addition to cases of moral behaviour without (much) meaning, there appear to be ones of immorality with some meaning. Suppose, say, the only way to save the life of one's spouse were to steal a scarce medicine from a public hospital. Such behaviour would surely be wrong, at least in some major respects, but would probably make one's life more meaningful. Recall, too, the influential case of Gauguin, reputed to have ditched his wife and children so as to pursue his painting career in Tahiti.

If meaningfulness (and what is meant by related terms such as 'significance' and 'importance') is not identical to happiness and rightness, then what is it? In the field there are a number of ideas that have been suggested. ${ }^{5}$ According to some, to ask about the meaningfulness of a person's life is to ask whether it serves some purpose beyond obtaining pleasure for herself. For others, talk of 'meaning' connotes ideas of a positive relationship between the individual and something else that is good for its own sake such as another person, an artwork, or a theory. For still others, when thinking about meaning in a life, one is considering what about it might warrant certain emotional reactions such as great esteem or admiration. Finally, there is the idea that meaningfulness is a function of narrative, say, a matter of composing one's life-story.

It would be philosophically interesting to determine whether just one of these ideas, or some other one, uniquely captures all and only thought about meaning. However, for the sake of this article it will suffice simply to keep this cluster of them in mind, and to note that, for most philosophers, meaning is characteristically realized in

4 The next few paragraphs borrow from Thaddeus Metz, 'Life, Meaning of', in Encyclopedia of Global Bioethics, edited by Henk ten Have (Dordrecht: Springer, 2015), pp. 1-6.

${ }^{5}$ Critically discussed in Metz, Meaning in Life, pp. 17-36. 
the three contexts of the good (morality, beneficence), the true (enquiry, knowledge), and the beautiful (creativity, the arts).

A subjective account of meaning in life maintains that its constitution depends on the subject (where this subject need not be a spiritual substance). More carefully, subjectivism is the view that lives are meaningful solely in virtue of obtaining what the field calls objects of 'propositional attitudes', mental states such as wants, emotions, and goals that are about states of affairs. Propositional attitudes are characteristically capable of 'that clauses'; for example, one has a desire that something were the case, or one is proud that something is true of one.

The subjectivist maintains that there is no standard independent of people's propositional attitudes to determine which states of affairs are meaningful. Instead, for her, states of affairs are meaningful just insofar as they are objects of propositional attitudes that have been obtained.

For example, what makes it the case that being a chess grandmaster is meaningful or not, for the subjectivist, is entirely determined by the attitude that someone (or some group) has taken (or would take) towards it. If I had wanted to be a chess grandmaster, and if I succeeded in becoming one, then typical subjectivists would claim that meaning would be conferred on my life in virtue of having obtained the object of my desire. If I had wanted to be a chess grandmaster, and if I failed to become one, then standard subjectivists would claim that no meaning would have been conferred on my life.

The objectivist's defining claim is that subjective conditions such as a person getting what he wants or realizing his aims are not sufficient for his life to be meaningful. Instead, for the objectivist, certain states of affairs (perhaps in a merely physical world) are meaningful 'in themselves', apart from being the object of propositional attitudes. Some conditions are such that they ought to be wanted, chosen, or valued, even if people have not done so.

Returning to the chess grandmaster case, if an objectivist were to deem this project to be meaningful, she would appeal not merely to the fact that a person has adopted it, but instead (or at least also) to facts independent of this person's propositional attitudes, such as that taking up chess would: be intrinsically good because it is complex; develop facets of his rational nature; or improve others' quality of life by teaching them or entertaining them. If someone had a talent for chess but did not like it, or were not pursuing it, an objectivist might recommend that he change his mind, that he cultivate an interest in it, so as to bring more meaning to his life.

The neutral/non-neutral distinction is not about the respect in which meaning is or is not a function of propositional attitudes, but is instead, roughly, about the respect in which meaning, particularly its amount, is a function of a certain bearing on an individual, perhaps at a given time. Roughly, neutralists maintain that the amount of meaning to be had is independent of any orientation towards the state of a particular person, whereas non-neutralists maintain the opposite.

To illustrate, consider the context of prudential rationality, in which a neutralist might maintain that one ought to assign equal weight to the interests of one's present and future selves, whereas a non-neutralist might suggest that only the present matters or that it matters qualitatively more when making choices expected to promote her good. In addition, as I discuss below, a non-neutralist might, at a given time in her life, have a 
'bias towards the future' in respect of pleasure, in the words of Derek Parfit. ${ }^{6}$ That is, she might prefer to be someone who will experience a moderate amount of pleasure in the future than to be someone who already experienced a greater amount of pleasure in the past. In contrast, a neutralist with respect to one's life at a given time would prefer the greater amount of pleasure, giving no less weight to the past as to the future.

With respect to morality, the most important form of neutrality is consequentialism, the view that one morally ought to assign equal weight to everyone's interests regardless of whether they are members of your family or country, or that one has most moral reason to seek to minimize the number of harmful or degrading actions performed in the world regardless of who performs them. Deontology, in contrast, is often understood to maintain that it is permissible to give one's own interests or those of one's family extra weight, or that it is usually morally worse for oneself to perform a harmful or degrading action than it is to fail to prevent someone else from doing so.

To sum up, in these cases relating to prudence and morality, key debates are, roughly phrased, about whether one's present good matters more than one's future, whether one's future pleasure matters more than one's past, whether the interests of those related to one matter more than the interests of others, and whether one's own actions matter more than the actions of others. Although there is indeed some overlap with these issues in debates about meaning in life, these latter debates also, interestingly, feature some new areas of disagreement between non/neutralists.

Before turning to considerations of how non/neutrality figure into thought about what makes a life meaningful, consider how the distinctions drawn in this section bear on each other. Very roughly speaking, subjectivism tends towards non-neutrality, while objectivism tends towards neutrality. More carefully, I as now point out, the most resolutely non-neutral accounts of meaning in the literature have generally been subjective, and the most resolutely neutral accounts of meaning in the literature have been objective. However, there is no necessary, or for all I can tell, probabilistic, connection between these views; orthogonal accounts are plausible.

What we might call 'radically individualist' forms of subjectivism about meaning entail a kind of non-neutrality straightaway. If one believes, as Richard Taylor appeared to hold at one point in his career, ${ }^{7}$ that one's life is meaningful only insofar as one's desires are maximally satisfied, then it is only facts about one's self that constitute meaning, with facts about other people's desires or interests not mattering at all at a fundamental level (even if, contingently, one's desires might be about theirs). Consider, too, a communitarian account of meaning, according to which one's life is more meaningful, the more one lives up to norms of which one's society approves. ${ }^{8}$ Here, there is still non-neutrality of a sort, since it is facts about the propositional attitudes of one's society, not all human persons, that determine what is meaningful. However, there is a

\footnotetext{
6 Derek Parfit, Reasons and Persons (New York: Oxford University Press, 1984), pp. 165-166.

7 Richard Taylor, 'The Meaning of Life', in his Good and Evil (Amherst, NY: Prometheus Books, [1970] 2000), pp. 319-334.

8 Berit Brogaard and Barry Smith, 'On Luck, Responsibility, and the Meaning of Life', Philosophical Papers 34:3 (2005), pp. 443-458.
} 
form of subjectivism (which I have called 'hypothetical-intersubjective' ${ }^{9}$ ) by which meaning is constituted by facts about what all human selves would prefer from a certain standpoint and hence promises not to be 'biased', at least not in the ways the other subjectivisms are.

Turning to objectivism, what has been called the 'point of view of the universe' is a form of it that is usually held to entail neutrality. ${ }^{10}$ Suppose that facts about meaning are not a function of any human beings' propositional attitudes, and are instead determined either by what an impartial observer surveying the entire physical world would prescribe or by utterly mind-independent, natural facts about the amount of final value in it. Then, many would expect meaning in life to be a matter of performing whichever actions would maximize final values and minimize final disvalues, whomever may be affected and whenever they may obtain (and, perhaps, however they may be caused). This substantially neutral view of life's meaning has been clearly advanced by consequentialists who include Peter Railton, ${ }^{11}$ G. E. Moore, ${ }^{12}$ Peter Singer, ${ }^{13}$ Irving Singer, ${ }^{14}$ Quentin Smith, ${ }^{15}$ Aaron Smuts, ${ }^{16}$ Ben Bramble, ${ }^{17}$ and Mark Wells. ${ }^{18}$ It is a live position in Anglo-American debate about what constitutes meaning in life, and below I provide reason to reject it.

However, there are kinds of objectivism that are compatible with some nonneutrality. This sort of conception would be analogous to a natural rights account of moral duties. By this conception of right action, moral facts are not a function of any human beings' propositional attitudes and yet there is not equal moral reason for everyone to promote final value in any manner and at any location. Similarly, one objective but non-neutral approach to meaning is the view that facts about it are not a function of any human beings' propositional attitudes but that meaning does not obtain regardless of, roughly, whose good is advanced and when. Prominent examples include the accounts of life's meaning proffered by Robert Nozick, ${ }^{19}$ Susan Wolf, ${ }^{20}$ and myself. ${ }^{21}$

9 In Metz, Meaning in Life, pp. 168, 178. See, e.g., Stephen Darwall, Impartial Reason (Ithaca, NY: Cornell University Press, 1983), esp. pp. 164-166.

10 For some reason to doubt this claim, see Iddo Landau, 'The Meaning of Life Sub Specie Aeternitatis', Australasian Journal of Philosophy 89:4 (2011), pp. 727-734.

11 Peter Railton, 'Alienation, Consequentialism, and the Demands of Morality', Philosophy and Public Affairs 13:2 (1984), pp. 134-171.

12 Quoted in Metz, The Meaning of Life, edited by Hugh Moorhead (Chicago: Chicago Review Press, 1988), pp. 128-129.

13 Peter Singer, Practical Ethics, 2nd Edition (New York: Cambridge University Press, 1993).

14 Irving Singer, Meaning of Life, Volume 1: The Creation of Value (Baltimore: John Hopkins University Press, 1996).

15 Quentin Smith, Ethical and Religious Thought in Analytic Philosophy of Language (New Haven: Yale University Press, 1997).

16 Smuts, 'The Good Cause Account of the Meaning of Life'.

17 Bramble, 'Consequentialism about Meaning in Life'.

18 Wells, 'Meaning in Consequences'.

19 Robert Nozick, Philosophical Explanations (Cambridge, MA: Harvard University Press, 1981), pp. 594-613.

20 Susan Wolf, 'The True, the Good, and the Lovable: Frankfurt's Avoidance of Objectivity', in The Contours of Agency, Essays on Themes from Harry Frankfurt, edited by Sarah Buss and Lee Overton (Cambridge, MA: The MIT Press, 2002), pp. 227-244, and Meaning in Life and Why It Matters. 
For the three of us, meaning is relational, such that, e.g., helping children one has reared confers pro tanto more meaning than helping to the same degree those one has not, but it is not utterly relative to the propositional attitudes of subjects.

In the rest of this article, I try to avoid presuming that objectivism is true, and instead bracket the issue of whether and how meaning might be constituted by the objects of propositional attitudes. I instead critically explore respects in which meaning is neutral or not, considerations for which subjectivists and objectivists both probably need to account. I conclude that, although the kinds of agent-neutrality and patient-neutrality salient in various forms of consequentialism are implausible at this stage of debate about meaning in life, another sort of neutrality, in respect of a life's time, appears to be correct of meaning.

\section{Time}

When is meaning preferably realized in one's life? More specifically, is there a bias towards the future in respect of meaning in life, as there appears to be regarding pleasure? I argue that the answer to this question is complicated by the fact that there are two dimensions by which to evaluate the meaning in a life. In a part-life respect, which I explain below, meaning is time-neutral, but in a whole-life respect it is not. In both respects, however, I argue that the value-theoretic temporal structure of meaning differs from that of pleasure.

Recall above Parfit's point, roughly that one would typically prefer that pleasure be realized in one's future as opposed to have been experienced in one's past. More carefully, consider Parfit's thought experiment, in which you have just woken up from a surgery and are suffering from a temporary bout of amnesia. Before you are able to remember who you are, you are told that you could be one of two people. You could be either (A) someone who experienced a great amount of pleasure yesterday, or (B) someone who will experience a small amount of pleasure tomorrow. A large majority of readers would prefer to be (B), even though the amount of pleasure would be less. ${ }^{22}$ From this thought experiment, and from one about pain, ${ }^{23}$ Parfit infers that we have a 'bias towards the future' in the sense that, from the standpoint of any given time, we want our future to be as good as possible.

Thomas Hurka was perhaps the first to note that Parfit's generalization is too quick. We have a bias towards the future in respect of pleasure (and pain), but not, it

21 Thaddeus Metz, 'The Good, the True and the Beautiful: Toward a Unified Account of Great Meaning in Life', Religious Studies 47:4 (2011), pp. 389-409, and Meaning in Life, pp. 219-234.

22 It has been suggested to me that someone might prefer to be (A) since she could then obtain pleasure in the future from the memories of the pleasure she had experienced in the past. However, that point does not tell against the claim of bias towards the future, since the ultimate rationale here for preferring to be $\mathrm{A}$ is the prospect of future benefit.

23 If you could be either (A) someone who experienced a great amount of pain yesterday, or (B) someone who will experience a small amount of pain tomorrow, most would prefer to be (A), even though $(\mathrm{A})$ 's pain is larger. 
seems, in the case of goods that Hurka calls 'perfections', respects in which our valuable nature qua rational is realized.

Imagine that, awaking in hospital with temporary amnesia, you are told that you are either a scientist who made a major discovery last year or a different scientist who will make a minor discovery next year. You will surely hope that you are the first scientist. You will want your life to contain the greatest scientific achievement possible, regardless of its temporal location....This is captured in a fully time-neutral theory. ${ }^{24}$

Although below I suggest that the clause about temporal location is phrased too strongly, Hurka's central point seems correct and, upon reflection, to apply to more than merely perfections, which plausibly form a subset of meaningful conditions. ${ }^{25}$ For example, would you rather be someone who saved another person's life in the past, or someone who will help an old lady cross the street in the future? Presumably readers would prefer the former. Similarly, assuming that some meaning in life is a function of others' appreciation of what one has done, suppose that you could be either someone who had been widely recognized for having produced a masterpiece in the past, or someone who will be mildly recognized for having produced a mediocre poem in the future. Although I accept that there is some self-realization in both cases, the good of recognition is distinct from that and is part of the explanation of why one would rather be the former.

In general, I submit that we lack a bias towards the future, i.e., are neutral, with respect to goods for which it makes sense to feel great esteem, where meaningful conditions are plausibly identified as those (more or less - see the previous section of this article). Beneficent actions, scientific discoveries, aesthetic works (i.e., the good, the true, the beautiful) and recognition for these achievements are all plausible candidates for being estimable, or at least meaningful, and are ones that we would be glad to have had in the past, or, more carefully, to prefer to have had in the past, supposing they were substantial, than to be forthcoming in the future, supposing they were not.

There is a qualification to make, here, but it does not affect the overall point. The wrinkle is that Parfit's thought experiment as applied to meaning abstracts from 'wholelife' considerations, i.e., the respect in which meaning probably is constituted in part by the pattern of a life in its entirety, or at least for long stretches. Parfit's question invites one to focus on how a certain episode or project might confer meaning on one's life, and discourages one from considering whether a certain distribution of them over time might confer a distinct sort of meaning. However, a number of those working in the field have contended that a life's pattern makes a difference to its overall meaningfulness. ${ }^{26}$ All things being equal, for example, many think that a life with an upward trajectory of meaningful episodes and that ends on a high note is more meaningful as a whole than one without such a pattern, holding constant the degree of meaning inherent to the episodes considered as an aggregate.

24 Thomas Hurka, Perfectionism (New York: Oxford University Press, 1993), p. 61.

25 As I have argued in Meaning in Life, pp. 71-73.

26 Most thoroughly in Antti Kauppinen, 'Meaningfulness and Time', Philosophy and

Phenomenological Research 82:2 (2012), pp. 345-377. 
If this sort of whole-life dimension of meaning obtains, then it is wrong to suppose that there is only time neutrality regarding when meaning is preferable in a life. It is too strong, or at least is misleading, to say, as Hurka does above, that one wants one's life 'to contain the greatest scientific achievement possible, regardless of its temporal location'. That seems true when comparing achievements considered in themselves. However, it is probably false when considering a life as a whole, in which case one would prefer that one's career progresses to the point of making the greatest scientific achievement possible at the end, rather than peter out afterwards.

In sum, when it comes to the question of when meaning is preferable in a life, there is some neutrality and some non-neutrality. When considering meaningful projects in themselves, there is neutrality, in the sense that one would prefer to have had a very meaningful project in the past than to have a not so meaningful one in the future. There is no bias towards the future in the sense of wanting the future to be as meaningful as possible, if it would mean a much less meaningful past. However, when considering the overall distribution of meaningful projects, there does appear to be such a bias; at least many of us would prefer that meaning increase over the course of our lives.

In both respects, meaningfulness interestingly differs from happiness qua pleasant experiences and a hedonist account of prudence based on that construal. For one, there is arguably no neutrality when it comes to pleasure; we invariably would prefer that pleasure come in the future, no matter how small it will be, than that it already occurred, no matter how large it was. For another, the reason we want pleasure invariably to come in the future does not appear to be a function of whole-life considerations. It is not the pattern of a life that moves us to want the future to be as pleasant as possible, as it is in the case of meaning; for what motivates us in Parfit's thought experiment is, recall, nothing about life as a whole. Instead, it appears that there is something about the nature of a positive experience that makes it such that, in respect of its final value, it is something always to want to undergo as opposed to something to want to have undergone.

\section{Agents}

The previous section was about when meaning in life is preferably exhibited from the standpoint of an agent at a given time. The present section is, in contrast, about the respect in which meaning in life is a function of an agent having caused certain outcomes. Suppose that meaning is, at least to some degree, constituted in some way by advancing finally good states of affairs such as making other people's lives go better. Can one obtain meaning in a life merely by having brought about (perhaps in some particular way) something good for its own sake, or must one have both brought it about and thereby added to the overall amount of final value in the universe that would not have obtained were it not for one's having so acted?

Some consequentialists contend that the latter is true, that in order to have had a meaningful life, one must have made the world a better place than it would have been without one. Such a view is neutral in the sense that it is not sufficient merely to be one who has done some good. Beyond that, for some consequentialists, one must have added some net sum of good to the world that would not have been realized otherwise. 
G. E. Moore is clearly a consequentialist of this sort. In a response to a written query about his views on life's meaning, he once said,

I have been very much puzzled as to the meaning of the question 'What is the meaning or purpose of life?'...But at last it occurred to me that perhaps the vague words of this question are often used to mean no more than 'What is the use of a man's life?'....A man's life is of some use, if and only if the intrinsic value of the Universe as a whole (including past, present, and future) is greater, owing to the existence of his actions and experiences, than it would have been if, other things being equal, those actions and experiences had never existed. ${ }^{27}$

To have a useful, and hence meaningful, life by Moore's view, one must have contributed to the production of a certain state of affairs that abstracts in a neutral fashion from one's position, namely, to the aggregate of what is good for its own sake wherever it exists in the world. Ben Bramble has recently advanced a similar view. ${ }^{28}$

Quentin Smith is still another theorist who holds this account of the conditions for a meaningful life, but he interestingly believes that they are never fulfilled and that everyone's life is therefore meaningless. ${ }^{29}$ For Smith, in order for our lives to matter, we must be in a position to add some amount of final value to the universe, but we are never in such a position since the amount of final value of the world is already infinite. The key premises for this view are that every bit of space-time (or at least the stars in the physical universe) have some positive final value, that these values can be added up, and that space is infinite. If the physical world at present contains an infinite degree of value, nothing we do can make a meaningful difference, for infinity plus any amount of value must be infinity.

To question Smith, as well as Moore and Bramble, I do not address the metaphysical issue of whether space is infinite or the axiological one of whether there already exists an infinite amount of final value. Instead I focus on the claim that having meaning in one's life requires one having made the universe better, qua higher sum of final value over all spaces and times, than it would have been without one having lived. Even granting that there is already an infinity of final value, meaning would be possible if it did not require adding a certain amount of value to the world, but instead obtained upon being the source of a desirable outcome.

Consider that one does not merely want one's child to be reared with love, but wants to be the one who rears one's child with love. This desire remains even knowing that others would have reared one's children with love in one's absence, so that one's actions would not be increasing the final value of the state of the universe relative to what it would have had without them. Even if a step-father would have appeared on the scene and produced the same effects on my children, it is intuitive to think that some meaning accrues to my life for an agent-relative consideration, namely, for in fact having been the one to have produced these effects.

27 Quoted in Moorhead, The Meaning of Life, pp. 128-129.

28 Bramble, 'Consequentialism about Meaning in Life', p. 450.

29 Quentin Smith, 'Moral Realism and Infinite Spacetime Imply Moral Nihilism', in Time and Ethics: Essays at the Intersection, edited by Heather Dyke (Dordrecht: Kluwer Academic Publishers, 2003), pp. 43-54. 
For another example, nearly all of us working in intellectual fields would be proud, and reasonably so, if we were the first to make an important discovery. Our sense of pride is not dependent on the idea that the discovery would not have been made had we not done so. We usually expect others to make the discoveries we do, in time, but we sensibly feel esteem if we were nonetheless the ones to have initially made them. Or consider that if one swam out in the sea, against a rough current, to rescue someone drowning and so at some risk to one's life, then one would be reasonable to take some pride in having done so, even if someone else would have done so had one not. Supposing, as per a previous section, that meaning is largely constituted by pride-worthy conditions, the discovery and the rescue would have conferred some meaning on one's life. ${ }^{30}$

For a final point, consider how counterintuitive an analogous principle is. Suppose one suggested that one would not have done wrong to kill an innocent person against his will for money because, if one had not done so, someone else would have done the same. The fact that someone else would have reduced the amount of final value in the world had one not is no reason to think that one has not acted wrongly in doing so. Similarly, the fact that someone else would have produced the amount of final value in the world had one not is no reason to think that one has not accrued some meaning in life in having produced it.

These and myriad similar cases suggest the principle that what matters is not so much that a certain amount of final value would not have existed had one not brought it about, but more that one is the cause of final value, even if it would have been produced in one's absence. Meaning can come from one making the world better than it was, even if ones does not make it better than it would have been without one. Note that rejecting the more neutral interpretation of meaning does not require one to forego consequentialism about meaning altogether. It is coherent to deem Aaron Smuts to be a consequentialist insofar as he maintains that 'one's life is meaningful to the extent that it promotes the good', that is, 'objective value in the universe', ${ }^{31}$ regardless of 'whether the same good would have resulted if one had not existed'. ${ }^{32}$

\section{Patients}

This section addresses the question of whether it matters where one does some good. More carefully, supposing that meaning can be conferred by promoting well-being or excellence, does the amount conferred logically depend on whose well-being or excellence is? A neutral theory would answer 'no', unlike a more biased, partial, or relational one.

One natural angle by which to address this issue would be consideration of personal relationships. Would more meaning come from benefitting to some degree the

\footnotetext{
30 Bramble mentions a similar case, of wading in shallow water to save a life, but the ease of the rescue is a confounding factor, I believe, inclining one to judge differently. See his 'Consequentialism about Meaning in Life', p. 450.

31 Smuts, 'The Good Cause Account of the Meaning of Life', p. 558.

32 Ibid., p. 536.
} 
child whom one loves or to a somewhat greater degree a stranger's child whom one does not love, supposing that their present levels of well-being were comparable (and, so, it is not as though the stranger's child is starving and one's child is not)?

Although I do believe that partial relationships provide grounds for questioning neutrality in the sphere of meaning, I doubt that the way in which they do is distinct from parallel debates that have taken place in the literature on morality over the past two decades. If one believes either that partiality is either inherent to morality and can override impartial elements of it, or that it can override morality as such sometimes (à la Bernard Williams), then one is surely going to think that considerations of meaning are partial to some degree as well.

Since that path of debate has been well trod, I raise some less familiar considerations about whose good to foster, insofar as doing so is meaning-conferring. They concern not a choice between a beloved and a stranger, but instead between a beloved and oneself. A fully neutral theory about whose good should be advanced when it comes to meaning would give one one's own good the same weight as anyone else's. I argue, however, that, depending on the sort of good involved, there are situations in which one's own good should receive either more weight or less than others'.

Focus first on the good of subjective well-being, which I presume to be constituted at least in large part by pleasure. A neutral theory entails that, insofar as promoting subjective well-being confers meaning on the one doing the promoting, promoting one's own well-being could confer meaning on one's life to a degree comparable to promoting someone else's well-being. However, this implication is counterintuitive. ${ }^{33}$

For one illustration of the problem with patient-neutrality, consider Angry Dog, a case in which you and a friend are unexpectedly exposed to a fierce, medium-sized canine that, while unlikely to kill either of you, does threaten to draw blood. Suppose that you and your friend's influences on other people's well-being would be equal, that you are marginally more pain sensitive than your friend, that the dog will catch at least one of you (and, to be complete, that the dog would find no difference in pleasure upon catching either of you). A neutral theory such as utilitarianism would entail that, of the actions available, escaping would confer the most meaning on your life, even if this required shoving your friend in an apparently accidental manner towards the dog (and then forgetting about what you did). However, I submit that your life would not be made any more meaningful for so acting, and that the meaningful course would instead be to enable your friend to escape.

For an additional example, think about Mum. In this case, a mother is considering giving up food for her young son, where we suppose that both are quite hungry and that the food would do her somewhat more good than it would him. A neutral theory entails that more meaning would accrue to the mother by eating the food herself (and staving off guilt) than by giving it to her son, since she would thereby promote the greatest amount of well-being in the universe. However, this is implausible; the mother's life would be no more meaningful for enhancing her own welfare. If there is

33 The following cases are similar to a thought experiment I first presented in Thaddeus Metz, 'Utilitarianism and the Meaning of Life', Utilitas 15:1 (2003), pp. 50-70 at pp. 56-57. 
a meaningful action here, it would be sacrificing her own good for the sake of her son's, even when this would result in a bit less welfare overall.

The cases suggest that the promotion of your own welfare, at least subjectively construed, even when this constitutes promoting the most welfare available in the world, cannot enhance the significance of your life, or, more carefully, at least that pleasure promotion cannot enhance the significance of your life when the gains to you would be marginal relative to others. Interestingly, intuitions are reversed when the relevant good is not subjective well-being but rather excellence, perfection, or virtue.

Consider the case of Married Couple, ${ }^{34}$ both of whom are talented, indeed so talented that they have precisely calculated that the most intellectual and practical virtue would be produced in the long run if the wife stayed home and supported the husband in his professional career, more than if he instead took care of the household or if they both worked and shared the domestic labour of cleaning, cooking, and caretaking. Suppose that the amount of extra virtue realized by the husband through his work would be marginal relative to the other options. Since, according to a neutral approach, meaning is proportionate to the overall amount of virtue produced, wherever that may be, the wife ought to stay home and support the husband on grounds of meaning. However, that is counterintuitive. Even if the wife had worked hard at home to enable her husband to perfect his human nature, to a slightly higher degree than that of which she were capable, she would have had more meaning in her life, insofar as it is a function of excellence, if she had instead exhibited quite a lot of excellence in herself.

In response to this case, Mark Wells has suggested that part of its pull is a function of many readers' inclination to reject patriarchal norms. That is, we are inclined to judge that the wife ought not stay at home, not so much because of considerations of meaning, but rather because many of us do not want to see women saddled with traditional roles. Wells remarks, 'As a critic of such traditional patriarchal norms - a position I suspect I share with many other academics - I cannot be sure my judgment about the meaningfulness of the wife's life is not being influenced by the appearance of these norms'. ${ }^{35}$

The point is fair. However, the next issue to consider is whether parallel cases render the same conclusion when shorn of such confounding elements. And I submit that they do. For a first one, switch the positions of the husband and wife. Suppose that marginally more virtue would be produced in the world if he stayed home than if they both worked and did the domestic chores. Even so, reasons of meaning, to the extent they are grounded on excellence, counsel him to realize substantial excellence in himself, even if doing so would come at some minor cost to the net sum of excellence existing in the universe.

Similar remarks go for athletes and their coaches. Although some meaning surely accrues to a coach for enabling an athlete to flourish, more meaning would have come to her life had she been in the position of the athlete. ${ }^{36}$ The familiar phrase 'He who can,

\footnotetext{
34 First advanced in Metz, Meaning in Life, p. 195.

35 Wells, 'Meaning in Consequences', p. 173.

36 Wells remarks of a similar sort of case, 'When I modify the case to be about two teammates rather than a wife and her husband, I am less willing to say that teammate who sacrifices for the other
} 
does; he who cannot, teaches' is disparaging plausibly because of the sense that more meaning would come from doing than teaching how to do. Of course, to teach something well often means being able to do it well. The point is that more meaning tends to come from actually doing something well oneself, as opposed to enabling others to do so to a marginally greater degree.

Consider, too, musicians and those who sort out the logistics necessary for them to practice and play for audiences. Which would you rather be, the pianist or the one who pushes the piano onto the stage to enable her to play? Although there is some meaning in enabling others to develop and exhibit their aesthetic excellence, there would be somewhat more meaning, when it is grounded on aesthetic excellence, in being the one to display this excellence. There are, therefore, many cases beyond Married Couple that support the judgement that it is particularly important, insofar as meaning tracks the realization of virtue, to manifest virtue in oneself.

Notice that I do not deny that there is real meaning to be had in being a coach, a teacher, or even the guy who pushes the piano onto the stage so that the pianist can exhibit her talents. In addition, I make no claim about whether, in these sorts of cases, one ought to develop the excellence in oneself all things considered; perhaps a moral reason to help others means that one should on balance enable them to realize their virtue, even though it would be a bit less than the amount one would exhibit. I merely claim that meaningfulness, to the extent that it is a function of non-moral excellence in the realms of sport or music, is such that one has pro tanto more reason to develop the excellence in oneself than in others.

Furthermore, I do not mean to suggest that one always has most reason to promote athletic or aesthetic virtue in oneself, if one has to choose between oneself and others. I readily agree that if someone else would exhibit a much greater degree of this sort of virtue than oneself, then reasons of meaning, insofar as they are a function of promoting non-moral virtue, would entail enabling her to do so. The core point is that there appears to be an independent reason of meaning of some weight to exhibit such virtue oneself.

Reflect, now, on the two sets of cases I have advanced, one concerning well-being and the other virtue. Both have served the function of providing reason to doubt a neutral account of where to promote good in order to obtain meaning thereby. The cases of well-being suggest that, all things being equal, one obtains more meaning by enhancing the well-being of others than that of oneself, whereas the cases of virtue suggest that, all things being equal, one obtains more meaning by developing virtue within oneself than helping others to develop it in themselves. Although both sets of cases provide strong reason to doubt neutrality, one naturally hankers for an explanation of why the two goods have an inverse structure. Part of the explanation might be grounded on the definition of meaning-talk provided above. If 'meaning in life' by definition involves (at least to a large degree) the pursuit of higher-order purposes beyond one's own pleasure, then doing what would avoid causing one pain or would bring oneself pleasure could not (as such) confer meaning.

thereby lives less meaningfully' ('Meaning in Consequences', p. 173). Wells is 'less' willing to say it, but perhaps still willing on balance? 


\section{Means}

The last major debate about neutrality in the context of life's meaning in recent literature concerns how to bring about good in a meaning-producing way. One facet of this discussion concerns moral constraints (or restrictions or rights), and whether good produced in the wake of their violation can confer meaning or not. Since, however, I appear to have said the most recent word on that matter (namely, 'it depends on the nature of the constraint'), ${ }^{37}$ I do not address it, and instead focus on a different issue, concerning the respect in which the manner one produces good affects the amount of meaning involved. It concerns whether the means towards a desirable end must be effortful, sophisticated, or otherwise employ one's rational nature in a robust way. Neutralists contend that they need not be, that it does not matter what the agent does, so long as the results are (expected to be) good. I have argued that it does matter, but three consequentialists have recently argued that I am incorrect. I here respond to their rationales.

Central to the debate is Robert Nozick's old hypothetical case of a Results Machine ${ }^{38}$ programmed to bring about an array of desirable outcomes upon a certain button on it being pressed. If the means taken towards the end of maximizing the world's amount of good were irrelevant, then, as I have contended, a maximally meaningful life would be one that programmed the machine, or pushed the relevant button, so as to bring about as much objective value as it could. However, that judgment is counterintuitive. Even if it were the case that one ought to get the machine running, one's life would not be maximally meaningful for having done so. Instead, a fully meaningful life, insofar as it involves the promotion of objective value, requires effortful or hands on activity. ${ }^{39}$

In hindsight, I should have acknowledged that building or programming the machine could well have counted as an effortful or hands on activity. However, I continue to hold that merely pressing a button on it would not, and hence would not make one's life all that meaningful.

Those who maintain that meaning is a function of maximizing good, whichever actions may be sufficient to do so, have responded in four major ways to this thought experiment. First, Smuts has suggested that pressing a button would not be the real cause of the good produced, and so for that reason would not confer meaning even by a consequentialist view. He remarks, 'By pressing the button one might play a causal role in the process, much like the presence of oxygen plays in arson. But it's not clear that this is the cause we are after when we want to know why our house went up in flames.' 40

Although it would be reasonable to ascribe most responsibility to the designer of the machine itself, it does not seem right to suggest that the one who presses the button would be akin to oxygen in the arson scenario, a merely necessary background condition. Instead, the stronger analogy, I submit, is one in which the person responsible for the

37 Metz, Meaning in Life, pp. 189-195.

38 Robert Nozick, Anarchy, State, and Utopia (New York: Basic Books, 1974), pp. 42-45.

${ }^{39}$ Metz, Meaning in Life, pp. 194-195.

40 Smuts 'The Good Cause Account of the Meaning of Life', p. 557. 
machine's existence is like the person who has provided the match, and the person who presses the button on the machine is like the person who strikes the match.

A second reply, from Bramble, is that perhaps 'what is leading Metz to think that my ability to press the button does not make my life maximally meaningful now is that he is assuming that the button is easy to press, so that if I did not press it somebody else would.' 41 Bramble then invokes the extremely neutral version of consequentialism discussed earlier in this article, contending that meaning in life is constituted by making 'a contribution to good things that would not otherwise be made' and imagining that no one else would indeed press the button. ${ }^{42}$

I have of course provided reason to doubt this version of consequentialism above. However, another point to make is that what moves my intuition in the thought experiment is that little meaning is present not so much because someone else would readily press the button, but rather because pressing the button is easy. It does not take great strength of will, sophisticated planning, substantial training, fine discrimination, and so on. Even if I knew no one else would press the button, say, because the button requires my fingerprint alone to operate, I have the judgement that, while some meaning would accrue thereby, not as much meaning would accrue as if the same outcome were produced with a more robust exercise of my rational nature.

Bramble has a third reply, which is that I might be conflating final and instrumental sorts of meaning. If one presses the button, there is no other meaningful activity to come in its wake, but if one were instead to produce the same good by using one's rational nature in an effortful, complex way, then one would probably be in a position to produce even more good down the road. ${ }^{43}$ It is this ability to do more good in the long run, Bramble suggests, that is moving me to think there is more meaning in the latter case than in the former.

However, it is not the idea that pressing the button would not be instrumentally good in the long-term that is moving me. When I imagine someone on his deathbed, with not much time left to live, I continue to have the intuition that the sort of deliberation and volition he undertakes is relevant to how much meaning he is going to get from his last days. Imagine, on the one hand, that he could merely reach over and press the button, or, on the other, that he could creatively and strategically coordinate the activities of a diverse group of people towards a common end, or engage in some tricky financial transactions to fund a project.

The fourth and final reply to the Results Machine thought experiment is the most interesting and initially appears to be powerful. Both Smuts and Wells have suggested that what the friend of neutrality ought to say is that there can be final value present in certain actions themselves, not merely in what results from the actions. In Smuts' words, button pressing lacks 'achievement value', a plausible final good constitutive of meaning. ${ }^{44}$ Wells similarly suggests that 'robust, active, or intense means contribute to

41 Bramble, 'Consequentialism about Meaning in Life', pp. 450-451.

42 Ibid., p. 450.

43 Ibid., p. 450.

${ }^{44}$ Smuts, 'The Good Cause Account of the Meaning of Life', p. 558. 
the final goodness of the consequence they produce', ${ }^{45}$ either by virtue of being good in themselves or contributing to a means-ends organic whole that is good for its own sake.

Here is why this tempting reply is not convincing: it runs afoul of the point made in the previous section, namely, that it is, all things being equal, better to display virtue in oneself than to enable others to do so. Imagine the choice were either to display achievement value oneself and thereby produce good outcomes, on the one hand, or to press the button on the Results Machine that would prompt two others to display achievement value and thereby produce good outcomes, on the other. The neutralist must prescribe the latter course of action, but the intuition remains that this would not confer as much meaning on one's life as exemplifying achievement value oneself. In short, how one acts matters.

\section{Conclusion}

Recall the three aims of this article. One has been to identify the major lines of debate between neutralists and non-neutralists in the context of the value of meaning in life, to the extent that the latter is a function of realizing some independent final good. On this score I have identified four major disputes, concerning when meaning is preferable in a life, whether being the source of good is sufficient for meaning, whether meaning depends on whose good is promoted, and whether meaning depends on the manner in which one promotes good.

A second aim has been to defend particular answers to these questions. I argued that, in respect of parts of a life, meaning is time-neutral, or at least is not biased towards the future, for most would prefer to have a very meaningful project in the past than to have a not so meaningful one in the future. However, in all other respects, I have argued that meaning is biased, partial, relational, or otherwise non-neutral. Considering life as a whole, most would prefer to end their lives on a high note of substantial meaning. It appears to many that being an agent who is the source of good would be sufficient to confer meaning on one's life, even if others would have produced the same amount of good in the absence of one's activities. It seems that it does matter whose good is promoted, such that advancing one's own pleasure tends not to confer as much meaning as advancing that of others, and developing others' virtue tends not to confer as much meaning as developing one's own. Finally, the way in which one produces good is intuitively relevant to the degree of meaning available, such that button-pressing produces pro tanto less meaning than does the robust exercise of one's rational nature. Any plausible theory of meaning in life, whether subjective or objective, must have something to say about these intuitive features of it.

Finally, in having established these positions about meaning in life, a third aim of this article has been to contrast them with some salient views about prudence and morality. A hedonist account of prudence is, in contrast, time-biased for entailing that one would prefer a lesser amount of pleasure in the future than to have had a greater one in the past. A consequentialist account of morality is of course neutral when it comes to

45 Wells, 'Meaning in Consequences', p. 172. 
patients and means, entailing that it in principle does not matter whose good is promoted and in what manner.

It would be nice at this point to have an explanation of why meaning appears different, viz., to be non-neutral in all major respects except for one, regarding when meaning is preferable in a life (considering its parts in themselves). Why do reasons of meaning appear to exhibit the precisely inverse structure of utilitarian reasons of morality? Utilitarianism entails a bias towards the future as it includes the thesis of hedonism, is committed to the project of making people's lives go better, and therefore entails that their interests are at a given time always to experience more pleasure in the future. However, insofar as utilitarianism also includes consequentialism, it entails that an agent should be neutral about which persons are benefited and in what way, just so long as the maximum available sum of pleasure is produced. Meaning in life has the opposite features, entailing the time-neutral view that a person's interests are at a given time to perform or to have performed meaningful activities, and that it makes a difference which persons' good is advanced and in what way. Is there some deep reason for the inverse structure, and, if so, what is it?

One might object that the normative structure is not in fact inverse, since utilitarianism prescribes neutrality about time subject to the ability to influence states of affairs. That is, one might suggest that utilitarian reasons about morality are in principle time-neutral, and not biased towards the future, but that in practice they prescribe promoting pleasure only in the future because we cannot influence the past. If we could influence the past, so the objection goes, then utilitarianism would prescribe maximizing pleasure there, too.

While I accept that some forms of consequentialism are sensibly time-neutral, I do not think it is true of utilitarianism, insofar as the latter is the combination of consequentialism and a hedonist account of prudence. Recall Parfit's thought experiment, which reveals that, with regard to pleasure, we prefer it to come in the future, whereas with regard to meaning, we lack such a preference and welcome having exhibited it in the past. There is no awareness, here, of the ability to influence the past or not. One does not prefer future pleasures because one cannot influence the past, for otherwise one would also exhibit a bias towards the future in the case of meaning, but one does not.

The bias towards the future in respect of prudential pleasure, and hence of utilitarianism as a theory of moral reasons that includes it, is not in the first instance a function of the practical inability to change the past, but rather something else, something more principled. A thorough explanation of the time-bias of utilitarian moral reasons, their neutrality in respect of at least patients and means, and the fact that these reasons have the inverse structure of reasons of meaning, all must wait for another occasion. ${ }^{46}$

Thaddeus Metz, University of Johannesburg tmetz@uj.ac.za

46 This article has benefited from input received from: Dorothea Gädeke; participants at a Workshop on Meaning in Life and Objective Values held at Umeå University in Sweden; participants at a Conference on Neutrality: Reasons, Values, and Times held at Nanyang Technological University in Singapore; and a thoughtful anonymous referee for De Ethica. 


\section{Bibliography}

Bramble, Ben. 'Consequentialism about Meaning in Life', Utilitas 27:4 (2015), pp. 445-459.

Brogaard, Berit, and Barry Smith, 'On Luck, Responsibility, and the Meaning of Life', Philosophical Papers 34:3 (2005), pp. 443-458.

Darwall, Stephen. Impartial Reason. Ithaca, NY: Cornell University Press, 1983.

Hurka, Thomas. Perfectionism. New York: Oxford University Press, 1993.

Kauppinen, Antti. 'Meaningfulness and Time', Philosophy and Phenomenological Research 82:2 (2012), pp. 345-377.

Landau, Iddo. 'The Meaning of Life Sub Specie Aeternitatis', Australasian Journal of Philosophy 89:4 (2011), pp. 727-734.

Metz, Thaddeus. 'Utilitarianism and the Meaning of Life', Utilitas 15:1 (2003), pp. 50-70.

Metz, Thaddeus. 'The Good, the True and the Beautiful: Toward a Unified Account of Great Meaning in Life', Religious Studies 47:4 (2011), pp. 389-409.

Metz, Thaddeus. Meaning in Life: An Analytic Study. Oxford: Oxford University Press, 2013.

Metz, Thaddeus. 'Life, Meaning of', in Encyclopedia of Global Bioethics, edited by Henk ten Have. Dordrecht: Springer, 2015, pp. 1-6.

Moorhead, Hugh, ed. The Meaning of Life. Chicago: Chicago Review Press, 1988.

Nozick, Robert. Anarchy, State, and Utopia. New York: Basic Books, 1974.

Nozick, Robert. Philosophical Explanations. Cambridge, MA: Harvard University Press, 1981.

Parfit, Derek. Reasons and Persons. New York: Oxford University Press, 1984.

Railton, Peter. 'Alienation, Consequentialism, and the Demands of Morality', Philosophy and Public Affairs 13:2 (1984), pp. 134-171.

Singer, Irving. Meaning of Life, Volume 1: The Creation of Value. Baltimore: John Hopkins University Press, 1996.

Singer, Peter. Practical Ethics, $2^{\text {nd }}$ Edition. New York: Cambridge University Press, 1993.

Smith, Quentin. Ethical and Religious Thought in Analytic Philosophy of Language. New Haven: Yale University Press, 1997.

Smith, Quentin. 'Moral Realism and Infinite Spacetime Imply Moral Nihilism', in Time and Ethics: Essays at the Intersection, edited by Heather Dyke. Dordrecht: Kluwer Academic Publishers, 2003, pp. 43-54.

Smuts, Aaron. 'The Good Cause Account of the Meaning of Life', Southern Journal of Philosophy 51:4 (2013), pp. 536-562.

Taylor, Richard. Good and Evil. Amherst, NY: Prometheus Books, [1970] 2000.

Wells, Mark. 'Meaning in Consequences', Journal of Philosophy of Life 5:3 (2015), pp. 169179.

Wolf, Susan. 'The True, the Good, and the Lovable: Frankfurt's Avoidance of Objectivity', in The Contours of Agency, Essays on Themes from Harry Frankfurt, edited by Sarah Buss and Lee Overton. Cambridge, MA: The MIT Press, 2002, pp. 227-244.

Wolf, Susan. Meaning in Life and Why It Matters. Princeton: Princeton University Press, 2010. 
De Ethica. A Journal of Philosophical, Theological and Applied Ethics Vol. 4:3 (2017) 